\title{
DESEMPENHO AGRONÔMICO DE CULTIVARES DE LACTUCA SATIVA L. E BRASSICA OLERACEA var. CAPITATA EM SISTEMA AGROECOLOGICO CONSORCIADO SOMBREADO E NÃO SOMBREADO
}

\section{Gilma Rosa Nascimento_, José Augusto Tomaz de Faria², Deborah Neide de Magalhães Praxedes ${ }^{3}$, Diego Dantas Amorim³}

${ }^{1}$ Engenheira Agrônoma, Mestra em Produção Vegetal Titulada pela Universidade de Brasília (gilmarosanascimento@hotmail.com) Governador Valadares - Brasil.

${ }^{2}$ Tecnólogo em Gestão Ambiental Formado pelo Instituto Federal de Minas Gerais.

${ }^{3}$ Professor(a) Doutora da Área Acadêmica Ciências Biológicas, Meio Ambiente e Saúde do Instituto Federal de Educação, Ciência e Tecnologia de Minas Gerais, campus Governador Valadares.

${ }^{4}$ Professor Doutor da Área Acadêmica de Ciências Biológicas, Meio Ambiente e Saúde do IFMG, campus Governador Valadares.

Recebido em: 15/05/2020 - Aprovado em: 15/06/2020 - Publicado em: 30/06/2020 DOI: 10.18677/EnciBio_2020B21

\begin{abstract}
RESUMO
O enfoque agroecológico utiliza conhecimentos que possibilitam compreender as relações de complexidades entre os agrossistemas. As hortaliças folhosas são de grande importância no Brasil, mas seu cultivo em climas tropicais um desafio para os produtores, devido à baixa produtividade e má qualidade das folhas causadas pelo aumento da luminosidade e temperatura. Desta forma, em determinadas regiões e épocas do ano, faz-se necessário aprimorar tecnologias como o condicionamento climático e espacial para estas plantas. Assim, seguindo os princípios da agroecologia, o objetivo do trabalho foi avaliar comparativamente as características agronômicas das culturas do repolho e alface consorciado com bananeiras em sistema agroecológico sombreado e não sombreado. $O$ experimento foi desenvolvido na Chácara Ibituruna, estabelecida no munícipio de Governador Valadares/MG. Observou-se que a maior produção ocorreu a campo aberto, diferindo significativamente dos tratamentos em consórcio. Para o número de folhas por planta, constatou-se que houve diferença estatística entre os tratamentos cultivados em campo aberto para a alface e sombreados para o repolho, que apresentaram maior número de folhas. Observou-se que o repolho sob consórcio apresentou redução no diâmetro médio no e diâmetro do caule, sem, contudo, desqualificar o padrão comercial das plantas colhidas.
\end{abstract}

PALAVRAS-CHAVE: agroecologia, consórcio, hortaliças. 


\title{
AGRONOMIC PERFORMANCE OF LACTUCA SATIVA L. AND BRASSICA OLERACEA CULTIVARS var. CAPITATE IN AGROECOLOGICAL SYSTEM CONSORTIATED SHADED AND NOT SHADED
}

\begin{abstract}
ABSTRAT
The agroecological approach uses knowledge that makes it possible to understand the complex relationships between agrosystems. Leafy vegetables are of great importance in Brazil, but their cultivation in tropical climates is a challenge for producers, due to low productivity and poor leaf quality caused by increased light and temperature. Thus, in certain regions and times of the year, it is necessary to improve technologies such as climatic and spatial conditioning for these plants. Thus, following the principles of agroecology, the objective of the work was to comparatively evaluate the agronomic characteristics of cabbage and lettuce crops intercropped with banana trees in a shaded and non-shaded agroecological system. The experiment was developed at Chácara Ibituruna, established in the municipality of Governador Valadares / MG. It was observed that the largest production occurred in the open field, differing significantly from the treatments in consortium. For the number of leaves per plant, it was found that there was a statistical difference between the treatments grown in the open field for lettuce and shaded for cabbage, which had a higher number of leaves. It was observed that the cabbage under consortium showed a reduction in the average diameter and stem diameter, without, however, disqualifying the commercial standard of the harvested plants.
\end{abstract}

KEYWORDS: agroecology, consortium, vegetables.

\section{INTRODUÇÃO}

A Presidência da República decretou em 2012 a instituição da Política Nacional de Agroecologia e Produção Orgânica (PNAPO), que tem o "objetivo de integrar, articular e adequar políticas, programas e ações indutoras da transição agroecológica e da produção orgânica e de base agroecológica, contribuindo para o desenvolvimento sustentável e a qualidade de vida da população, por meio do uso sustentável dos recursos naturais e da oferta e consumo de alimentos saudáveis (LACEY; MARICONDA, 2014).

Segundo Ventura et. al. (2018), a agroecologia é uma ciência surgida na década de 1970, como forma de estabelecer uma base teórica para esses diferentes movimentos de agricultura não convencional. É uma ciência que busca o entendimento do funcionamento de agroecossistemas complexos, bem como das diferentes interações presentes nestes, tendo como princípio a conservação e a ampliação da biodiversidade dos sistemas agrícolas como base para produzir auto regulação e, consequentemente, sustentabilidade.

A agroecologia é uma vertente agronômica que engloba técnicas ecológicas de cultivo com sustentabilidade social (BESSA et al., 2016). Dentre as práticas agroecológicas, cita Sarmento et. al. (2019), que a adubação orgânica é importante para a produtividade de vários solos existentes, já que é fertilizante e agente estruturante. Melhora as características físicas, promovendo maior retenção de água, plasticidade e porosidade, mas o fornecimento de nutrientes e suas ações dependem do material usado.

Diversas práticas como o uso de estercos curtidos ou a aplicação de compostos, por exemplo, vêm sendo adotadas para suprir a crescente demanda por fertilizantes orgânicos (LIMA et al., 2015). Os compostos apresentam como vantagem a possibilidade de adequação pelos agricultores de cada região, de 
acordo com a disponibilidade de matéria-prima e a finalidade, além da exigência nutricional de cada cultivo, possibilitando um rendimento satisfatório e ecologicamente correto (REIS JÚNIOR et al., 2017).

O enfoque agroecológico corresponde à utilização de conhecimentos e princípios de diferentes campos do conhecimento científico e empírico, possibilitando compreender as relações de complexidades que perpassam pelos agrossistemas.

Os sistemas consorciados têm recebido atenção especial, principalmente pela riqueza de suas interações ecológicas, população de plantas, disposição espacial e manejo das lavouras no campo. Estes estão em contraste com os sistemas agrícolas modernizados, que são baseados na monocultura, uso intensivo de capital e produtos originários do setor industrial, como fertilizantes sintéticos e pesticidas (BATISTA, et. al., 2016).

Apesar dos benefícios resultantes do consórcio entre diferentes espécies vegetais, inexistem estudos sobre a viabilidade de se associar a cultura da alface (Lactuca sativa L.), considerada a hortaliça folhosa de maior importância no Brasil, originária de países de clima temperado, o que torna seu cultivo em climas tropicais um desafio para os produtores, devido à baixa produtividade e má qualidade das folhas causadas pelo aumento da luminosidade e temperatura (GUERRA et al., 2017), com a banana, uma fruta originária das regiões tropicais da América do Sul, considerada um meio de sustentação de diversos produtores do Brasil, junto ao repolho (Brassica oleracea var. capitata), por conferir ao pequeno e médio produtor grande importância econômica e social (FILGUEIRA, 2008).

Além do baixo investimento inicial quando comparado a outras hortaliças, e devido ao retorno a curto prazo, o cultivo do repolho é estratégico e importante para o fortalecimento da agricultura familiar (XAVIER et. al., 2019).

A técnica da consorciação de culturas proporciona melhor aproveitamento dos recursos ambientais, tais como nutrientes, água e radiação solar. O cultivo de espécies com ciclos e arquiteturas vegetativas diferentes exploradas concomitantemente permite a maximização da mão-de-obra, aumento da produção por unidade de área, melhor distribuição temporal de renda e diversificação da produção. (TELLES et. al., 2015).

Para minimizar esse problema de baixa oferta de hortaliças orgânicas, em determinadas regiões e épocas do ano, faz-se necessário aprimorar tecnologias como o condicionamento climático para plantas, sobretudo para espécies como a alface, que apresentam baixa produtividade e qualidade quando cultivadas no verão, a espécie, sob altas temperaturas e luminosidade, desenvolve pendoamento precoce e folhas amargas, fibrosas e pequenas (SILVA, 2015).

Segundo Zandonadi et. al. (2014), a maioria das hortaliças cultivadas comercialmente é pouco eficiente na utilização de nutrientes. Como resultado, observam-se efeitos adversos nos solos relacionados ao excesso de adubação, o que além de ser caro, ainda resulta em danos ambientais.

Esta prática pode oferecer no cultivo de hortaliça dos agroecossistemas geridos pela agricultura familiar grandes vantagens. A possibilidade de colher hortaliças agroecológicas, expressando alto potencial produtivo, irá melhorar a condição alimentar das famílias, como também fará com que uma maior produção em um menor espaço permita aumentos na rentabilidade para o produtor familiar.

Seguindo os princípios da agroecologia, o objetivo do trabalho foi avaliar comparativamente as características agronômicas de duas culturas em sistema agroecológico sombreado, e não sombreado, através da técnica de associação de 
culturas, na produção de hortaliças, favorecendo o máximo de produção em um mínimo de área.

\section{MATERIAL E MÉTODOS}

O trabalho foi realizado em uma área particular denominada Chácara Ibituruna (Figura 1), situada na área rural do Morro do Urubu, no município de Governador Valadares, estado de Minas Gerais, localizada à margem do Rio Doce, entre o rio e o Monumento Natural Pico da Ibituruna. Suas coordenadas do ponto central são: latitude $-18^{\circ} 51^{\prime} 59^{\prime \prime}$ oeste, longitude $-41^{\circ} 56^{\prime} 03^{\prime \prime}$ sudoeste, altitude $160 \mathrm{~m}$. Trata-se, na sua quase totalidade, de uma vertente orientada para o Noroeste e, por isso, ensolarada durante a maior parte do dia e do ano, desde poucos momentos após o nascer do sol. O clima na região, segundo classificação de Köppen é o tropical de savana (Aw), (ALVARES, 2013).

O solo da área é classificado como Latossolo amarelo eutrófico de textura média 32\% de argila (EMBRAPA, 2013).

Figura 1. Área de estudo - Chácara Encosta do Sol Governador Valadares/MG

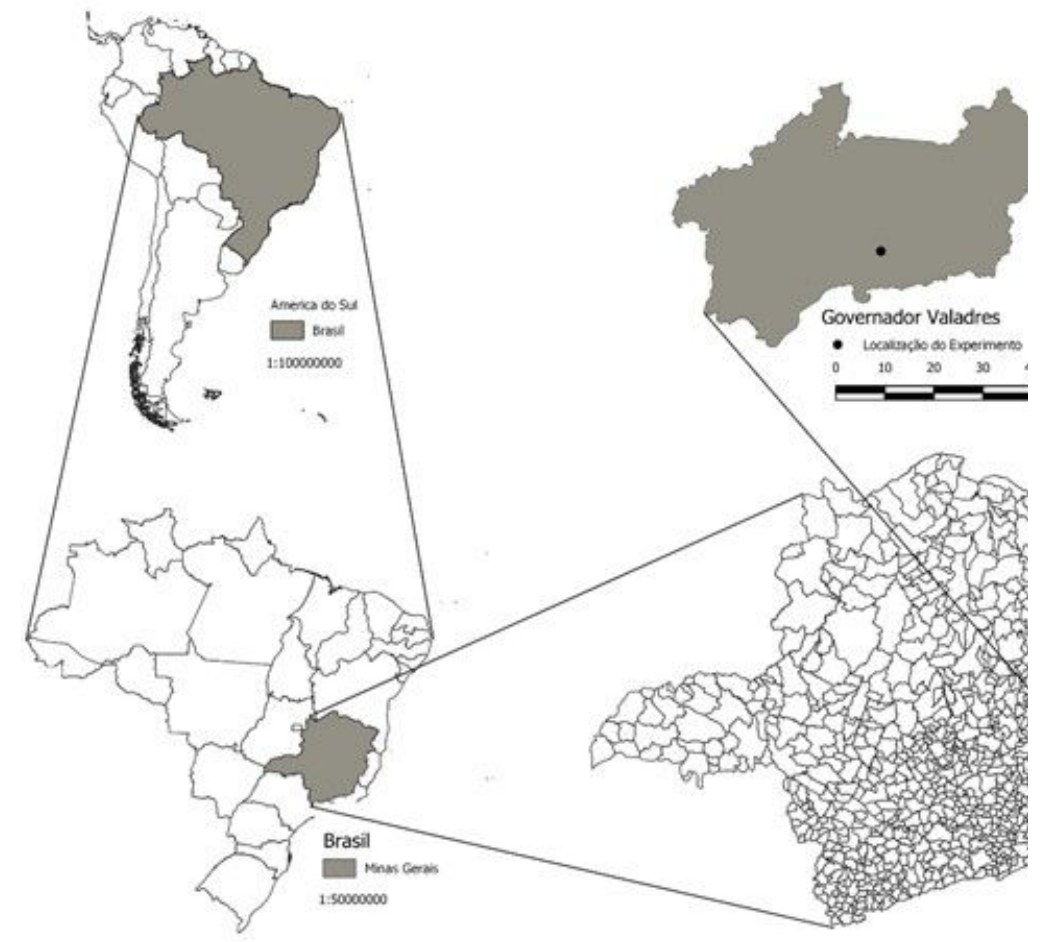

Fonte: IBGE, 2018.

Dois tipos de hortaliças foram avaliados em consórcio - alface do tipo crespa Camila (Lactuca sativa L.) e repolho do tipo Liso (Brassica oleracea var. capitata), com plantio de bananeiras já se desenvolvendo no local, e em monocultivo, e a forma de plantio utilizada foi o orgânico em plantio direto.

O transplantio das mudas foi feito para o campo entre linhas das bananeiras já possuindo $2 \mathrm{~m}$ de altura, em sistema orgânico e direto, em canteiros. $\mathrm{O}$ preparo do solo foi realizado com uma aração manual na profundidade de $0,15 \mathrm{~m}$. Posteriormente foi realizado o preparo das linhas com 1,00 m de largura, contendo duas linhas com espaçamento de $0,30 \mathrm{~m}$ entre linhas e entre plantas tanto para a alface quanto para o repolho (Figura 2). 
O delineamento experimental utilizado foi de blocos ao acaso, com dois fatores em esquema de parcelas subdivididas com quatro repetições. Cada parcela foi constituída por área de 2,50m x 1,20m, composta de duas fileiras intercaladas de plantas com espaçamento de $30 \mathrm{~cm}$ entre linhas e de $25 \mathrm{~cm}$ entre plantas, em que cada parcela continha 16 plantas. Os tratamentos foram, T1 - consórcio com bananeiras (sombreado), T2 - plantio sem bananeiras (não sombreado). A área entre as bananeiras foi dividida em 4 parcelas experimentais. Os dados foram submetidos à análise de variância e teste de Scott-Knott, a 5\% de probabilidade. Os ensaios foram conduzidos no verão.

Figura 2. Canteiros de alfaces e repolhos em delineamento de blocos ao acaso, sombreados e não sombreados. Fotos $A$ e $B$, Canteiros de alface e repolho em plantio sombreado; C e D, plantio sem sombreamento.
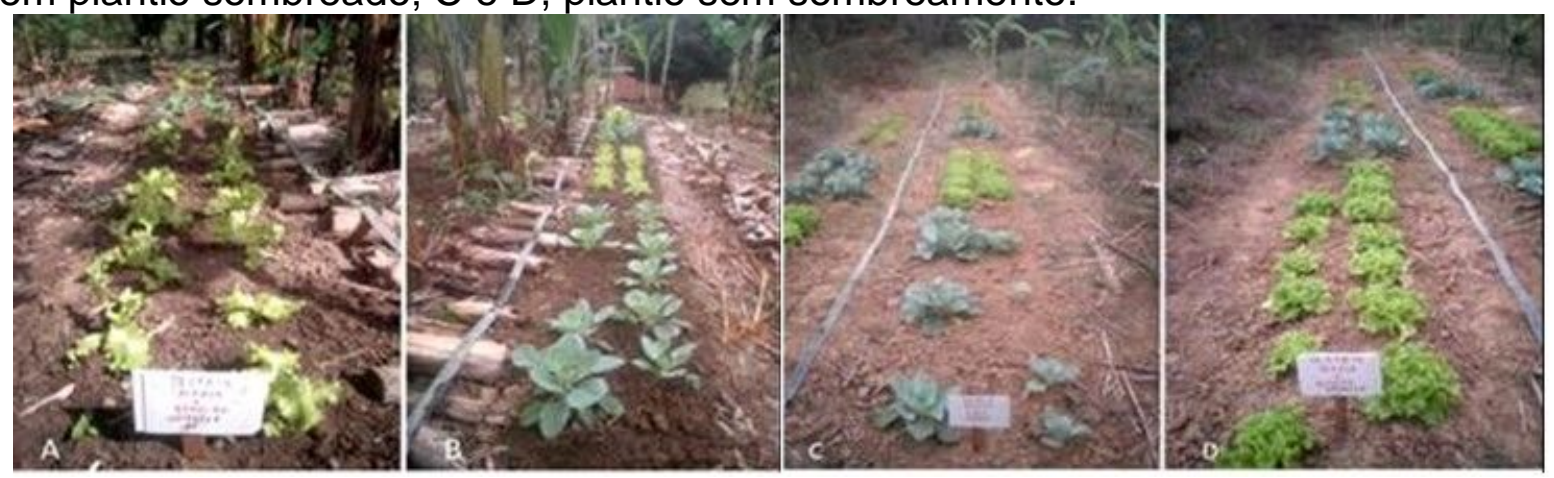

Fonte: Próprio autor.

Em ambos os experimentos, as adubações foram feitas com $500 \mathrm{~g} / \mathrm{m}^{2}$ de composto orgânico (1 parte de cama de frango, 2 partes de esterco bovino) aos 20 dias após a semeadura. Foram realizados os tratos culturais permitidos para 0 cultivo orgânico (MAPA, 1999; BRASIL, 2011).

A irrigação foi por aspersão tradicional, havendo também pulverizações semanais na fase vegetativa, com defensivos caseiros para controle de pragas. Durante o ciclo das culturas, foram realizadas capinas com enxada, entre os canteiros e, manualmente entre as plantas. $\mathrm{Na}$ área utilizada para o estudo já havia plantio de bananeiras do tipo prata e nanica, com 12 meses, que foram utilizadas para sombrear a área de desenvolvimento das hortaliças, com afastamento de $3 \mathrm{~m}$ entre linhas e $2 \mathrm{~m}$ entre plantas. As folhas das bananeiras foram utilizadas, quando em senescência para proteção do solo. Esta prática de proteção manteve o solo úmido favorecendo as bananeiras.

Aos 60 dias, aproximadamente, após o transplantio da alface e aos 120 dias após o transplantio do repolho, foi realizada a colheita através do corte das plantas rente ao nível do solo. Foi feita a avaliação da produção, que consiste na massa da matéria fresca da parte aérea ( $\mathrm{g} /$ planta), em que a parte aérea de cada planta foi separada das raízes e pesada em balança digital. Foram aferidos a largura da planta, a altura, o diâmetro e largura do caule. Foram considerados as folhas e os caules como usualmente são comercializadas. Apenas as folhas exteriores em processo de senescência foram removidas. A análise das bananeiras em consorcio em relação as plantas em área sem o consorcio foram visuais.

\section{RESULTADOS E DISCUSSÃO}

Os resultados da análise de variância das características agronômicas avaliadas nos dois tratamentos podem ser observados nas Figuras 3 e 4. 
Em relação à altura da folha não houve diferença significativa entre os tratamentos para as duas hortaliças, indicando que nesse parâmetro os arranjos de consórcio não influenciaram a cultura. Também com relação à avaliação do diâmetro e largura do caule, o estabelecimento dos arranjos de consórcio não alterou o desempenho produtivo das culturas. Para a largura da folha, verificou-se que o cultivo de alface em sistema orgânico sombreado comportou-se semelhantemente ao observado sob sistema tradicional em campo aberto, no entanto, para este parâmetro, o repolho apresentou média maior no cultivo sombreado $(43,33 \mathrm{~cm}$ e $30,11 \mathrm{~cm}$, sombreado e não sombreado, respectivamente). Em campo, pôde ser notado nitidamente que o repolho sob consórcio apresentou redução no diâmetro de folhas e diâmetro do caule, o que não foi corroborado estatisticamente, pois observando a figura 4 , gráfico $B$, pode-se notar que não há diferenças comprovada na largura da folha.

Figura 3: Análise de variância das características agronômicas de cultivares de alface (Lactuca sativa L.) A, e repolho (Brassica oleracea var. capitata) B: largura e altura da folha, diâmetro e altura do caule, sob sistemas de consórcio com banana (Musa ssp.), sombreado, e sem consorcio, não sombreado.
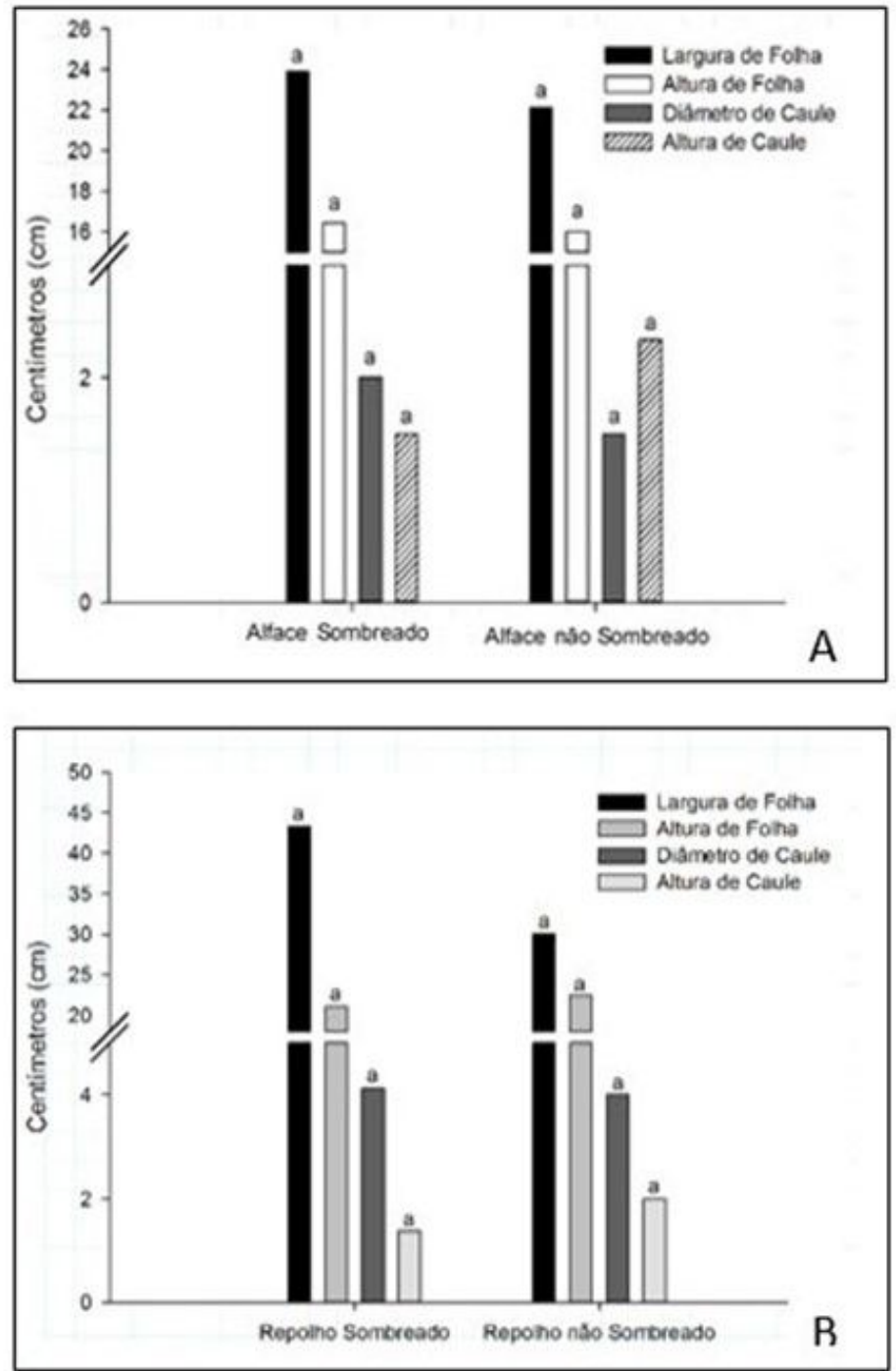

Fonte: Próprio autor. 
Ao avaliar o desempenho de cultivares de alface sombreadas Silva (2015), obteve resultados distintos em todos os plantios, sendo melhor desempenho na produção sombreada, em contraste aos resultados deste estudo. Já estudo realizado por Telles (2015), o desempenho produtivo da cultura da alface, em consórcio com hortaliças tradicionais (bertalha e taro), em arranjos de consórcio duplo e triplo, não registrou diferença significativa na produção de massa fresca de alface em nenhum dos tratamentos. Esta pesquisa corrobora com os resultados discutidos na Figura 3.

Figura 4: Análise de variância da Massa Fresca (A) e Número de Folhas (B) de cultivares de alface (Lactuca sativa L.), e repolho (Brassica oleracea var. capitata), sob sistemas de consórcio com banana (Musa ssp.), sombreado, e sem consorcio, não sombreado.
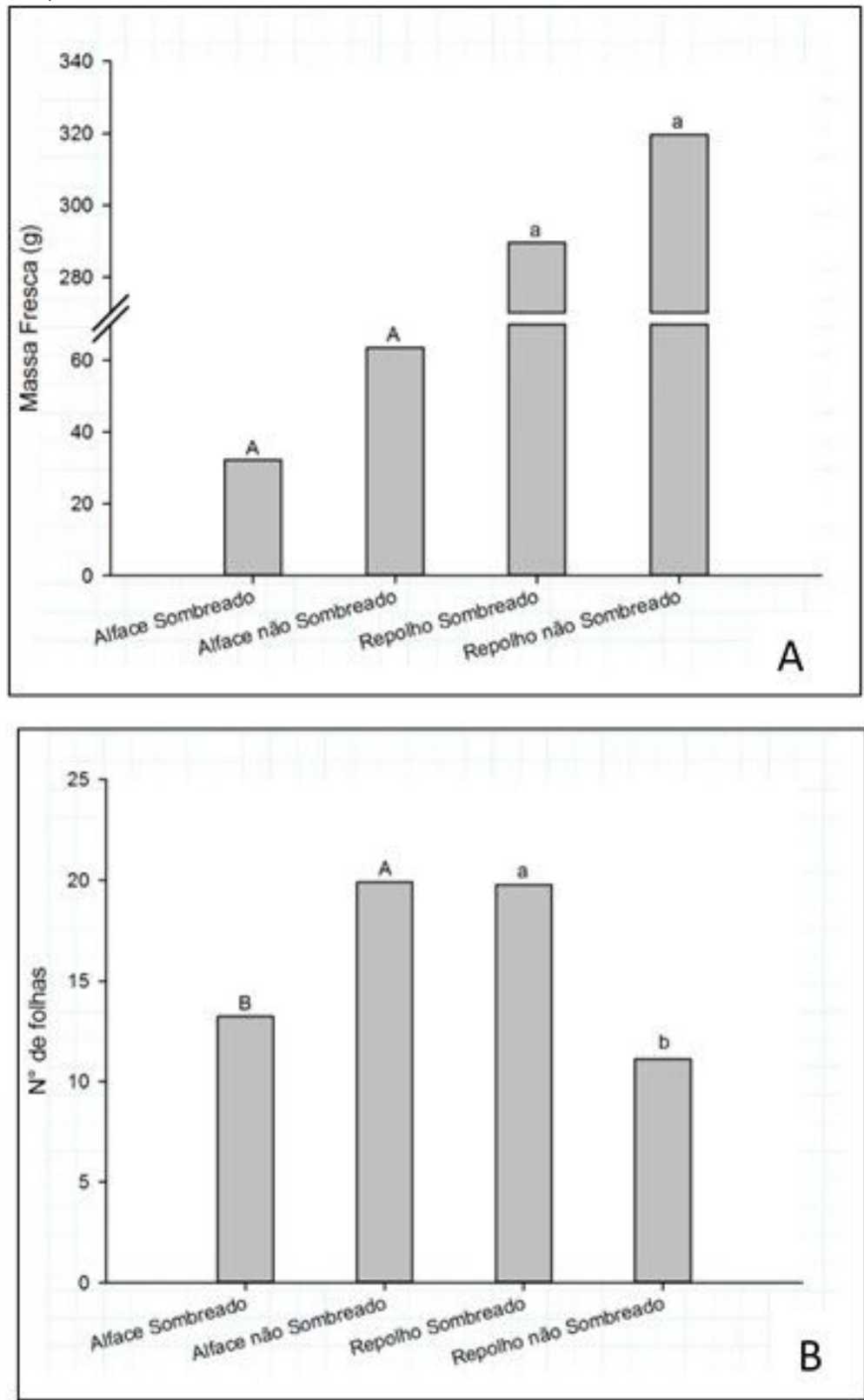

Fonte: Próprio autor. 
Em estudos da ação da matéria orgânica sobre a fisiologia de hortaliças, Zandonati, (2014), relata que a maioria das hortaliças cultivadas comercialmente é pouco eficiente na utilização de nutrientes. Como resultado, observam-se efeitos adversos nos solos relacionados ao excesso de adubação, o que além de ser caro, ainda resulta em danos ambientais.

Batista (2016) ao avaliar hortaliças consorciadas, obteve resultados distintos, entre as interações, com isso atestando a importância da escolha das plantas a serem utilizadas. As mudanças na densidade de plantio ou através de um aumento disponibilidade de radiação, afetam indiretamente a distribuição de matéria entre órgãos vegetais.

O local do estudo, nunca antes tinha recebido nenhum outro tipo de cultivo de hortaliça. Durante o experimento as bananeiras se apresentaram bem viçosas, com aumento da altura e no número de folhas quando comparadas as outras bananeiras que se desenvolviam fora da área experimental. Podendo assim observar o benefício de solo úmido para as bananeiras, que se mantiveram visivelmente saudáveis. Não houve colheita de frutas durante o experimento.

\section{CONCLUSÕES}

A cultura da alface não apresentou diferenças estatísticas nos tratamentos, apresentou diferença qualitativa, com folhas visivelmente de cor mais clara e maior turgescência. As plantas colhidas a pleno sol apresentavam tonalidade verde mais escura, e menor turgescência. Apresentaram produtividade boa para consumo e para comercialização, nos ambientes testados em comparação as alfaces comercializadas em feiras livres e mercados da região, tanto no consórcio sombreado quanto em campo aberto, ambos tiveram pequenos ataques na parte aérea das hortaliças por insetos: formiga e grilo.

A cultura de repolho apresentou comportamento melhor no cultivo onde o consórcio com bananeiras proporcionou sombra e manteve desempenho agronômico bom nos sistemas de cultivo investigados, quando comparados aos encontrados nas feiras e mercados da região, sendo poucos os casos de infestação por insetos.

Comparando as duas culturas entre si, podemos concluir que o repolho teve melhor desempenho consorciada sombreada, em relação a alface, usando como base as hortaliças comercializadas. $\mathrm{E}$ a alface teve desempenho melhor que 0 repolho em campo aberto, sem sombreamento. O consorcio de culturas no estudo apresentado trouxe o benefício do sombreamento as hortaliças, e o melhor aproveitamento da área.

As bananeiras tiveram aumento no número de folhas e menos ataque de pragas.

O consórcio com bananeiras demonstrou ser ideal para as condições estudadas, pois a qualidade da terra da área foi visivelmente melhorada, uma vez que a água utilizada na irrigação das hortaliças, era também aproveitada pelas bananeiras, onde assim propiciou um desenvolvimento das folhas do ponto de vista de manejo diário.

\section{REFERÊNCIAS}

ALVARES, C. A., STAPE, J. L., SENTELHAS, P. C., MORAES, G. L., SPARAVEK, G. Köppen's climate classification map for Brazil. Meteorologische Zeitschrift, v.22, n.6, p.711-728, 2013. DOI: 10.1127/0941-2948/2013/0507 
BATISTA' T. M.V.; BEZERRA NETO, F.; SILVA I.N.; SILVA, M. L.; OLIVEIRA, E. Q.; BARROS JÚNIOR, A. P. Eficiência agronômica do consorcio de rúcula com cenoura sob diferentes populações. Rev. Caatinga [online]. 2016, vol. 29, n. 1, pp. 76-84. doi.org/10.1590/1983-21252016v29n109rc

BESSA, M. M.; VENTURA, M. V. A.; ALVES, L. S - Agroecologia, sustentabilidade e a necessidade dos movimentos agroecológicos se tornarem políticas públicas. Revista Desafios, v. 2, n. 2, p. 181-197, 2016. DOl: doi.org/10.20873/uft.23593652.2016v2n2p181.

BRASIL, Instrução Normativa $\mathrm{n}^{\circ}$ 46, de 06 de outubro de 2011. Regulamento Técnico para os Sistemas Orgânicos de Produção. Diário Oficial da União, Seção 1. Brasília, 07 de outubro de 2011.

INSTITUTO BRASILEIRO DE GEOGRAFIA E ESTATÍSTICA (IBGE). MAPA geográfico: sistema de projeção policônica: escala 1:10000000. Minas Gerais: 2018.

EMBRAPA. Centro Nacional de Pesquisa do Solo. Sistema brasileiro de classificação de solos. (2. ed.) Brasília: Embrapa. 353p. 2013.

FILGUEIRA, F. A. R. Novo manual de olericultura: agrotecnologia moderna na produção e comercialização de hortaliças. Editora UFV, Viçosa. 2008.

GUERRA, A. M. N. M., COStA, A. C. M., \& TAVARES, P. R. F. - Atividade fotossintética e produtividade de alface cultivada sob sombreamento. Revista Agropecuária Técnica, 38(3), 125-132. 2017. doi.org/10.25066/agrotec. v.38i3.29246

LACEY, H.; MARICONDA, P. R. O modelo da interação entre as atividades científicas e os valores na interpretação das práticas científicas contemporâneas. Estudos Avançados, São Paulo, v.28, n.82, p.181-99. 2014. doi.org/10.1590/S0103-40142014000300012

LIMA, P. C., MOURA, W. M., ALMEIDA, C. H. S., SEDIYAMA, M. A. N., SANTOS, I. C. S. Agricultura orgânica e agroecologia: preparo do solo e adubação. Informe Agropecuário, 36, 7-18. ISSN 2358-6303. 2015.

MAPA - Ministério da Agricultura, Pecuária e do Abastecimento. Instrução Normativa Nº07 de 17 de maio de 1999. Diário da República Federativa do Brasil, Brasília, DF.

REIS JÚNIOR, J. R., TOLEDO, M. V., SANDRI, D. M., SILVA, J. C. B. V. Defensivos alternativos: recomendações práticas para transição agroecológica. Instituto Emater, Curitiba. 2017.

SARMENTO, J. J. A.; SANTOS, J. J. F.; COSTA, C.C.; BOMFIM, M.P. Agronomic performance of lettuce subjected to green manure with different leguminous species, Revista Brasileira de Engenharia Agrícola e Ambiental Campina Grande, PB, v.23, n.2. p 114-118. 2019.doi.org/10.1590/1807-1929/agriambi

SILVA, E. M. N. C. P.; FERREIRA, R. L. F.; RIBEIRO, SOUZA, A. M. A.; ARAÚJO NETO, S. E.; KUSDRA, J. F. - Desempenho agronômico de alface 
orgânica influenciado pelo sombreamento, época de plantio e preparo do solo no Acre. Pesq. Agropecuária. Brasileira. vol.50 no.6 Brasília June/2015. doi.org/10.1590/S0100-204X2015000600005

TELLES, C. C.; FUKUSHI, Y. K. M.; BASTOS, P. R. P.; LAPA, L. P. A.; JUNQUEIRA, A. M. R.- Cultivo de alface em consórcio com hortaliças tradicionais. Cadernos de Agroecologia - Vol. 10, № 3. ISSN 2236-7934. 2015.

VENTURA, M. V. A.; BESSA, MARCIO M.; ALVES, L. S.; CHAGAS, P. C. S.; COSTA, E. M.; ARANTES, B. H. T. Agroecologia e agricultura ecológica como pilar de sustentação da agricultura camponesa. Multi-Science Journal, v. 1, n. 12 13-16. 2018. doi.org/10.33837/msj.v1i12.611

XAVIER, M. C. G.; SANTOS, C. A.; COSTA, E. S. P.; CARMO, M. G. F. Produtividade de repolho em função de doses de bokashi. Revista de Agricultura Neotropical, Cassilândia-MS, v. 6, n. 1, p. 17-22. jan/mar. 2019. https://doi.org/10.32404/rean.v6i1.2372.

ZANDONADI DB; SANTOS MP; MEDICI LO; SILVA J. Ação da matéria orgânica e suas frações sobre a fisiologia de hortaliças. Horticultura Brasileira 32: 14-20, 2014. doi.org/10.1590/S0102-05362014000100003. 